\title{
Towards One Health Knowledge Networks: A Southern African Centre of Infectious Disease Surveillance case study
}

\author{
Author: \\ Eric Beda ${ }^{1}$ \\ Affiliation: \\ ${ }^{1}$ Southern African Centre \\ for Infectious Diseases \\ Surveillance, Sokoine \\ University of Agriculture, \\ Tanzania \\ Correspondence to: \\ Eric Beda \\ Email: \\ eric.beda@sacids.org \\ Postal address: \\ PO Box 3297, Morogoro, \\ Tanzania \\ How to cite this poster: \\ Beda, E., 2012, 'Towards \\ One Health Knowledge \\ Networks: A Southern \\ African Centre of Infectious \\ Disease Surveillance case \\ study', Onderstepoort Journal \\ of Veterinary Research 79(2), \\ Art. \#480, 1 page. http:// \\ dx.doi.org/10.4102/ojvr. \\ v79i2.480 \\ Note: \\ Proceedings of the \\ Conference of the Southern \\ African Centre for Infectious \\ Disease Surveillance 'One \\ Health' held at the National \\ Institute for Communicable \\ Diseases, Johannesburg, July \\ 2011.
}

C 2012. The Authors Licensee: AOSIS OpenJournals. This work is licensed under the Creative Commons Attribution License.
The dynamic nature of new information and/or knowledge is a big challenge for information systems. Early knowledge management systems focused entirely on technologies for storing, searching and retrieving data; these systems have proved a failure. Juirsica and Mylopoulos ${ }^{1}$ suggested that in order to build effective technologies for knowledge management, we need to further our understanding of how individuals, groups and organisations use knowledge.

As the focus on knowledge management for organisations and consortia alike is moving towards a keen appreciation of how deeply knowledge is embedded in people's experiences, there is a general realisation that knowledge cannot be stored or captured digitally. This puts more emphasis in creating enabling environments for interactions that stimulate knowledge sharing.

Our work aims at developing an un-obtrusive intelligent system that glues together effective contemporary and traditional technologies to aid these interactions and manage the information captured. In addition this system will include tools to aid propagating a repository of scientific information relevant to surveillance of infectious diseases to complement knowledge shared and/or acts as a point of reference.

This work is ongoing and based on experiences in developing a knowledge network management system for the Southern African Centre of Infectious Disease Surveillance (SACIDS), A One Health consortium of southern African academic and research institutions involved with infectious diseases of humans and animals in partnership with world-renowned centres of research in industrialised countries. 